\title{
فعالية برنامج تشجيع اللغة في ترقية مهارة الكلام لطلاب الجدد بالمعهد الحديثة خادم الأمة جزر رياو
}

\author{
Ramandhan Rudwi Hantoro \\ STAIN Sultan Abdurrahman Kepulauan Riau \\ ramandha@stainkepri.ac.id
}

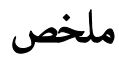

برنامج Tasyji'ul Lughoh هو برنامج مصمم لتحسين مهارة كلام الطلاب ملاب

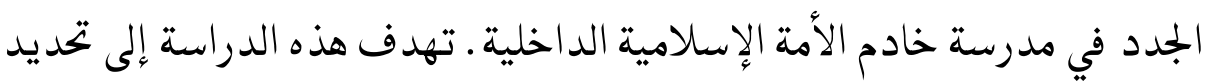

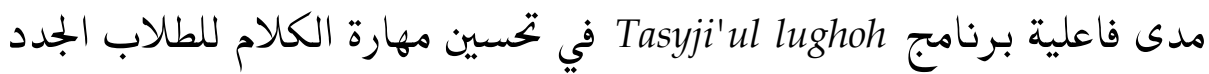

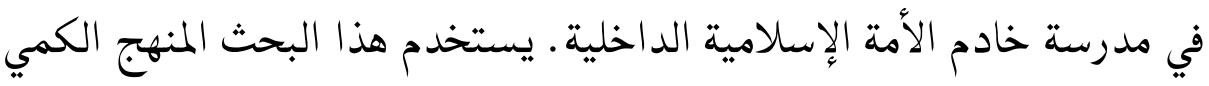

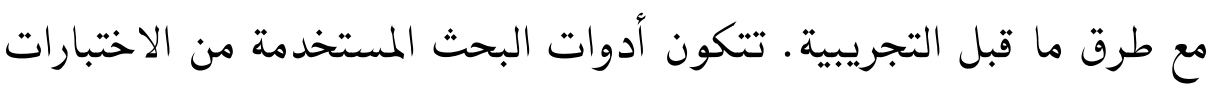

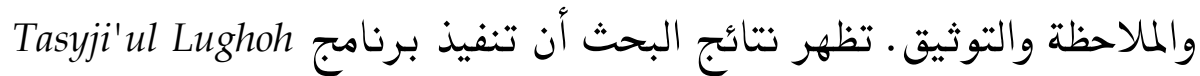

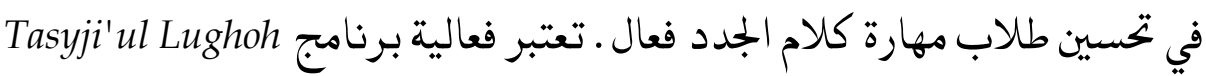
لتحسين مهارة كلام للطلاب الجدد في فئة جيدة جدًا بنسبة عه ٪ (بالمائة).

\section{Pendahuluan}

الكلمات المفتاحية : تصميم اللغة ، مهارة الكلام.

Maharah Kalam (keterampilan berbicara) merupakan satu dari empat keterampilan yang harus dikuasai oleh santri dalam mempelajari bahasa Arab, tiga keterampilan lainnya, yaitu: qira'ah (membaca), kitabah (menulis), dan sima'iyah (mendengar). Maharah kalam memiliki tingkat kesulitan yang lebih rumit dari pada tiga keterampilan lainnya, dimana dalam aspek ini santri dituntut 
Ramandhan Rudwi Hantoro : فعالية برنامج تشجيع اللغة في ترقية مهارة الكلام لطلاب الجدد بالمعهد الحديثة خادم الأمة جزر رياو

untuk memiliki perbendaharaan kosa kata yang banyak, memiliki kemampuan mendengar dengan baik, dan kemampuan untuk mengungkapkan apa yang dia rasakan dengan tepat dan sesuai dari segi kaidah tatanan kebahasaan maupun topik pembicaraan. ${ }^{46}$

Beberapa hambatan yang biasa ditemui dalam menguasai keterampilan bahasa terletak pada proses pembelajarannya. ${ }^{47}$ Bahasa Arab memiliki kaidah-kaidah yang banyak dan rumit dibandingkan dengan bahasa lainnya dari segi kebahasaan, seperti: arti kata, kosa kata, dan kaidah yang berkaitan dengan gramatika yang kompleks. kompleksitas aspek kebahasaan tersebut menjadikan pembelajaran bahasa Arab harus menggunakan metode pengajaran yang tepat dan inovatif supaya para pelajar pemula mudah dalam memahami bahasa Arab. ${ }^{48}$

Fatimah mengatakan bahwa problematika pembelajaran bahasa Arab akan terurai apabila dalam pembelajaran mampu menerapkan praktek bahasa secara langsung dan mengintegrasikan antar maharat..$^{49}$ Karena bahasa menurutnya bukan hanya persoalan

${ }^{46}$ Ahmad Fuad Mahmud 'Ilyan, al-Maharat al-Lughawiyah wa Tharaiqa Tadrisiha, (Riyadh: Darul Muslim Lin Nasyr wat Tauzi', 1431), hlm. 96

47 Acep Hermawan, Metodologi Pembelajaran Bahasa Arab, (Bandung: PT Remaja Rosdakarya, 2011), hlm. 99

48 Umar Assasudin Sokah, Problematika Pengajaran Bahasa Arab dan Bahasa Inggris, (Yogyakarta: Nur Cahaya, 1982), hlm. 12

49 Maharaat (مهارات) kata jamak dari Mahir (ماهر), memiliki arti pandai. Istilah maharat digunakan dalam bahasa Arab untuk menunjukkan kepandaian dalam kebahasaan yang memiliki empat aspek: membaca, menulis, mendengar dan berbicara. Pembahasan ini dapat dilihat dalam: Hasan Ja'far al-Khalifah, Fushul fi Tadris al-Lughoh al-'Arabiyah, (Riyadh: Maktabah al-Rusyd, 2002), hlm. 72 
Ramandhan Rudwi Hantoro : فعالية برنامج تشجيع اللغة في ترقية مهارة الكلام لطلاب الجدد بالمعهد

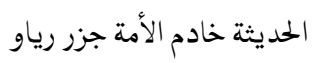

memahami kosakata dan susunan kalimat saja akan tetapi tujuan dari belajar bahasa asing adalah agar bisa berkomunikasi dengannya. Jika pengajar mampu menjadi guru bahasa bukan ahli bahasa maka santri akan lebih mudah memahami dan mempraktekan bahasa. ${ }^{50}$

Pondok Pesantren Khadimul Ummah sebagai pondok pesantren modern menjadikan bahasa Arab sebagai bahasa utama dalam percakapan sehari-hari dan proses pembelajaran. Penerapan maharah kalam memiliki kendala bagi para santri baru dimana kebanyakan santri baru baru mengenal pembelajaran bahasa Arab di Pondok Pesantren. Kondisi ini memaksa pondok pesantren mencarikan solusi yang bisa mengupayakan para santri baru agar lebih cepat memahami dan mempraktekan bahasa Arab dalam keseharian. Sebagai solusi dari kondisi tersebut maka pondok pesantren Khadimul Ummah mencanangkan Program Tasyji'ul lughoh sebagai upaya meningkatkan kepandaian berbahasa arab bagi para santri baru.

\section{Pengertian Efektitias}

Efektivitas berasal dari kata dasar efektif, yaitu kata yang menunjukkan pengaruh, efek, atau akibat. ${ }^{51}$ Efektivitas juga bisa dimaknai dengan tercapainya hasil pada suatu kegiatan. Sebuah

50 Nur Habibah, Lingkungan Artifisial dalam Pembelajaran Bahasa Arab dalam dalam Arabiyat: Jurnal Pendidikan Bahasa Arab dan kebahasa araban UIN Syarif Hidayatullah, Vol. 3 No. 2 (September, 2016), hlm. 175

51 Tim Penyusun Pusat Bahasa, Kamus Bahasa Indonesia, (Jakarta: Pusat Bahasa, 2008), hlm. 374 
Ramandhan Rudwi Hantoro : فعالية برنامج تشجيع اللغة في ترقية مهارة الكلام لطلاب الجدد بالمعهد الحديثة خادم الأمة جزر رياو

program bisa dikatakan efektif jika seluruh kegiatannya terlaksana dengan baik dan mencapai hasil yang diinginkan. Keberhasilan sebuah pembelajaran setidaknya meliputi dua hal, yaitu: berhasil dalam proses dan berhasil mencapai tujuan belajar yang diinginkan. ${ }^{52}$ Keberhasilan dalam proses setidaknya apa yang dilaksanakan dalam pembelajaran sesuai seperti yang sudah direncanakan. Sehingga dapat dikaji apakah pelaksanaan dalam pembelajaran telah sesuai dengan apa yang direncanakan. Keberhasilan pembelajaran dari segi hasil dapat dilihat dari seberapa banyak santri yang berhasil menyelesaikan seluruh tujuan pembelajaran dengan waktu yang sudah ditentukan.

Kriteria keefektivan dapat dikategorikan menjadi 5 kategori, yaitu: sangat baik, baik, cukup, kurang baik, tidak baik. ${ }^{53}$ Berikut penjabaran secara rinci dengan persentase ditiap kategori:

Tabel 1. Kriteria Keefektifan Hasil Belajar

\begin{tabular}{|c|c|}
\hline Persentase yang memenuhi KKM $(\mathrm{N})$ & Kategori \\
\hline $80 \% \leq \mathrm{N} \leq 100 \%$ & sangat baik \\
\hline $60 \% \leq \mathrm{N} \leq 80 \%$ & Baik \\
\hline $40 \% \leq \mathrm{N} \leq 60 \%$ & Cukup \\
\hline $20 \% \leq \mathrm{N} \leq 40 \%$ & kurang baik \\
\hline $0 \% \leq \mathrm{N} \leq 20 \%$ & tidak baik \\
\hline
\end{tabular}

52 Siti Jaroyatun Ni'mah dan Muhammad Nasirudin, efektifitas Kitab 'Arabiyah linnasyiin untuk meningkatkan Maharah Qiraah dan Kalam di Kelas 1 Marhalah 2 Madrasah Diniyah Nurul Ummah Putri Kota Gede, dalam Maharaat: Jurnal Pendidikan Bahasa Arab UIN Sunan Kali Jaga, Vol. 2 No. 2 (April, 2020), hlm. 92.

53 Eko Putro Widoyoko, Evaluasi Program Pembelajaran, (Jogjakarta: Pustaka Pelajar, 2009), hlm. 242. 
Ramandhan Rudwi Hantoro : فعالية برنامج تشجيع اللغة في ترقية مهارة الكلام لطلاب الجدد بالمعهد

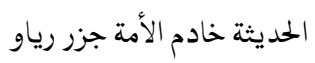

\section{Program Tasyji'ul Lughoh}

Program tasyji'ul lughoh merupakan program yang dirancang untuk santri-santri baru dalam mempercepat pemahaman berbahasa Arab dan mendorong para santri baru agar bisa mempraktekkan bahasa Arab sehari-hari. Progam ini dirancang karena melihat bahwa kemampuan bahasa santri akan lebih berkembang jika pembelajaran dilakukan tidak hanya di kelas tetapi juga lingkungan sekolah secara luas. Carol berpendapat bahwa pembelajaran melalui lingkungan di luar kelas akan lebih meningkatkan kemampuan berbahasa anak karena kesempatan yang digunakan untuk berlatih menggunakan bahasa lebih fleksibel dan luas. ${ }^{54}$

Materi dalam program ini mengambil tema-tema yang dekat dengan kehidupan sehari-hari santri, seperti: sekolah, asrama, ruang makan, kantin, dan lain sebagainya. Materi yang disampaikan memuat mufrodat (kosakata) dan hiwaar (percakapan). Pelaksanaan tasyji'ul lughoh dilakukan setiap hari setelah shalat Subuh selama kurang lebih setengah jam mulai dari jam 05.30 sampai dengan jam 06.00 wib. Selama 10 menit pertama ustadz akan menyampaikan mufrodat-mufrodat baru secara lisan dengan media gambar atau membawa benda secara langsung. Setiap ustadz menyebutkan satu kosakata dengan bantuan gambar santri secara bersama-sama mengikuti apa yang disampaikan ustadz.

54 Nur Habibah, Lingkungan Artifisial dalam pembelajaran Bahasa Arab dalam Arabiyat..., hlm. 176 
Ramandhan Rudwi Hantoro : فعالية برنامج تشجيع اللغة في ترقية مهارة الكلام لطلاب الجدد بالمعهد الحديثة خادم الأمة جزر رياو

\section{Maharah Kalam}

Terminologi maharah merupakan kata yang sering dipakai untuk menunjukkan sebuah "kemahiran", "kecakapan", dan "kepandaian" seseorang dalam berbicara menggunakan bahasa Arab.55 Sedangkan "kalam" (كلام), istilah tersebut merujuk pada perkataan seseorang yang dapat dipahami atau dimengerti. ${ }^{56}$ Kata kalam memiliki beberapa padanan kata, seperti: "pembicaraan", "perkataan", dan "percakapan" ${ }^{57}$ maharah kalam, atau lebih familiar disebut keterampilan berbicara, adalah kemampuan seseorang dalam mengungkapkan apa yang ada dipikirannya secara lisan dengan tepat dari segi huruf, kata, bunyi, maupun intonasi. ${ }^{58}$

Keterampilan berbicara memiliki tingkat kesulitan yang kompleks dibandingkan tiga keterampilan lainnya, yaitu: qira'ah (membaca), sima'i (mendengar), kitabah (menulis). ${ }^{59}$ Dalam hal berbicara seorang pelajar penting menguasai kemampuan mendengarkan yang baik, kemampuan menuturkan kata dengan benar, dan penguasaan kosa kata yang banyak sehingga seorang pelajar mampu mengungkapkan apa yang ingin dia ucapkan dengan kata-kata yang tepat dan sesuai. Maharah kalam (مهارة الكلام)

55 Tim Penyusun Pusat Bahasa, Kamus Bahasa Indonesia..., hlm. 896

56 Ahmad Fuad Mahmud 'Ilyan, al-Maharat al-Lughawiyah wa Tharaiga Tadrisiha..., hlm. 8

57 Ahmad Warson Munawwir, Kamus Bahasa Arab, (Surabaya: Pustaka Progresif, 2011), hlm. 1227.

58 Mahmud Kamil Al-Naqah, Ta'limul Lughah 'Arabiyah Linnathiqina bilughati ukhra, (Makkah: Ummul Qura University, 1985), hlm. 153.

${ }^{59}$ Ahmad Fuad Mahmud 'Ilyan, al-Maharat al-Lughawiyah..., hlm. 96 
Ramandhan Rudwi Hantoro : فعالية برنامج تشجيع اللغة في ترقية مهارة الكلام لطلاب الجدد بالمعهد الحديثة خادم الأمة جزر رياو

memiliki beberapa kriteria sehingga bisa dikatakan mahir dalam berbicara. Pendapat hermawan mengatakan bahwa seseorang dapat dikatakan mahir dalam berbahasa jika mampu mengungkapkan secara lisan pendapat, gagasan, maupun apa yang dirasakannya kepada lawan bicaranya secara tepat dan jelas. ${ }^{60}$ Berbeda dari Hermawan, Zaenudin memiliki pendapat bahwa tolak ukur maharah kalam jika seseorang mampu secara fasih mengucapkan bahasa Arab sesuai dengan Makharijul Huruf61_nya. ${ }^{62}$ Kedua pendapat diatas terlihat kontradiksi satu sama lain, dimana satu memfokuskan pada aspek bahasa sementara yang lainnya fokus pada hal-hal diluar yang mendukung kebahasaan. Kedua pendapat tersebut sejatinya tidaklah saling bertolak belakang melainkan saling melengkapi satu dengan yang lainnya.

Aspek kebahasaan, sebagaimana pendapat Zaenudin, dapat dikategorikan ke dalam beberapa hal, pertama: pengucapan yang sesuai dengan makhraj huruf-nya. Kedua, memiliki nada dan intonasi yang sesuai dengan bahasa asalnya. Ketiga, memiliki susunan kalimat yang sesuai dengan kaidah bahasa Arab, dan yang keempat,

${ }^{60}$ Acep Hermawan, Metodologi Pembelajaran Bahasa Arab..., hlm. 136

61 Makharijul Huruf (مخارج الحروف), secara leterlek memiliki arti tempattempat keluarnya huruf. Berbeda dari kebanyakan negara, negara di bagian Timur Tengah khususnya mereka yang menggunakan bahasa Arab sebagai bahasa sehari-hari memiliki aturan yang ketat dalam mengucapkan dan melafalkan huruf-hurufnya terutama ketika membaca al-Qur'an. Bahkan makharijul huruf menjadi salah satu materi wajib yang dipelajari dalam pelajaran tajwid.

62 Radliyah Zaenudin, Strategi Alternatif Pembelajaran Bahasa Arab, (Yogyakarta: Pustaka Rihlah Grup, 2005), hlm. 62 
Ramandhan Rudwi Hantoro : فعالية برنامج تشجيع اللغة في ترقية مهارة الكلام لطلاب الجدد بالمعهد الحديثة خادم الأمة جزر رياو

menggunakan kosakata yang tepat dan benar dalam percakapan. Kesemuanya ini dapat dijadikan tolak ukur kepandaian seseorang dalam bahasa arab jika ditinjau dari aspek kebahasaan. Aspek kedua, sebagaimana pendapat Hermawan, adalah aspek nonkebahasaan yang dapat dikategorikan ke dalam tiga hal, yaitu: syaja'atul kalam (keberanian dalam berbicara), kesesuaian topik, dan kelancaran dalam berbicara.

Dari penjabaran di atas, dapat disimpulkan bahwa maharah kalam memiliki dua aspek untuk dinilai yaitu: aspek kebahasaan dan non-kebahasaan. Oleh karena itu, dalam melakukan tes maharah kalam kriteria penilaian dapat disusun dengan melihat indikator pada tabel di bawah ini:

Tabel. 2 Aspek Penilaian Maharah Kalam

\begin{tabular}{|c|c|}
\hline Aspek yang dinilai & Indikator \\
\hline \multirow{3}{*}{ Kebahasaan } & Pengucapan (Makhraj) \\
\cline { 2 - 2 } & Intonasi (lahjah) \\
\cline { 2 - 2 } & Susunan kalimat (uslubul lughoh) \\
\cline { 2 - 2 } & Kosakata (mufrodat) \\
\hline Non-kebahasaan & keberanian dalam berbicara (syaja'atul kalam) \\
\cline { 2 - 2 } & kesesuaian topik (munasabatul madah) \\
\cline { 2 - 2 } & kelancaran dalam berbicara \\
\hline
\end{tabular}

\section{Proses Penelitian dan Hasil Analisis Data}

Penelitian ini menggunakan pendekatan kuantitatif. Sedangkan jenis penelitian penelitian yang digunakan adalah pre experimental dengan desain penelitian one group preetest-posttess design. Dalam penelitian ini menggunakan teknik penelitian sebagai berikut: 
Ramandhan Rudwi Hantoro : عبالية برنامج تشجيع اللغة في ترقية مهارة الكلام لطلاب الجدد بالمعهد

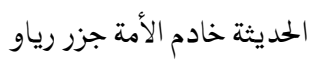

- Kegiatan observasi dilakukan untuk memperoleh data yang valid mengenai proses yang dilakukan pada program tasyji'ul lughah pada santri baru kelas 1 Pondok pesantren Khadimul Ummah. Selain proses mengajar kegiatan observasi juga bertujuan untuk mendapatkan data terkait dengan fisik pondok pesantren Khadimul Ummah dan kondisi pengajar pada pesantren tersebut.

- Tes yang diberikan kepada santri berupa tes lisan dengan indikator yang sudah ditetapkan oleh penguji. Tes pertama dilakukan sebelum santri mendapatkan pelatihan pada program tasyjij'ul lughah. Sedangkan tes yang kedua dilakukan setelah santri mendapatkan pelatihan pada program tasyjij'ul lughah.

- Uji validitas pada penelitian ini meggunakan rumus korelasi product moment, yaitu dengan rumus:

$$
r_{x y}=\frac{\sum x y}{\sqrt{\left(\sum x^{2}\right)\left(\sum y^{2}\right)}}
$$

Keterangan:

$\begin{array}{ll}\sum x y & =\text { jumlah perkalian } \mathrm{x} \text { dan } \mathrm{y} \\ x^{2} & =\text { kuadrat dari } \mathrm{x} \\ y^{2} & =\text { kuadrat dari } \mathrm{y}\end{array}$

Nilai $r$ tabel akan dikaitkan dengan nilai $r$ yang diperoleh sehingga akan disimpulkan jika $\mathrm{r}$ tabel lebih besar dari pada nilai $r$ yang diperoleh maka tes dinyatakan gugur. Sebaliknya jika $r$ tabel lebih kecil dari nilai $r$ yang diperoleh makan nilai dinyatakan valid. 
Ramandhan Rudwi Hantoro :

فعالية برنامج تشجيع اللغة في ترقية مهارة الكلام لطلاب الجدد بالمعهد :

الحديثة خادم الأمة جزر رياو

Sedangkan uji realibilitas penelitian ini menggunakan teknik pengukuran koefisien dari alpha cronbach dengan rumus sebagai berikut:

$$
\text { Alpha }=\frac{K}{k-1}\left(1 \frac{\sum s j^{2}}{s x^{2}}\right)
$$

Keterangan:

$\mathrm{K}=$ = banyaknya belahan tes

$\mathrm{Sj}^{2} \quad=$ varians $\mathrm{j} ; \mathrm{j}=1,2,3 \mathrm{dst}$.

$\mathrm{Sx}^{2} \quad=$ varians skor total

Nilai preetest dan posttest tentang efektivitas akan dilihat persentase kenaikannya dengan melihat jumlah nilai santri yang mengalami kenaikan menggunakan rumus persentase, yaitu:

$$
P=\frac{\sum x}{n} \times 100 \%
$$

Keterangan:

$\mathrm{P} \quad=$ persentase

$\mathrm{n} \quad=$ jumlah santri

$\sum n=$ jumlah santri yang mengalami kenaikan

Efektifitas Program Tasyji'ul Lughah Terhadap Kemampuan Maharah Kalam Siswa

Program taysji'ul lughah yang dilakukan dalam penelitian ini mengambil tema adawatul yaumiyah (الأدوات اليومية), peralatan seharihari. Tema ini memuat kosa kata dan penerapannya pada percakapan sehari-hari. Pembelajaran dimulai dengan membacakan kosa kata oleh ustadz yang kemudian diikuti oleh 
Ramandhan Rudwi Hantoro : فعالية برنامج تشجيع اللغة في ترقية مهارة الكلام لطلاب الجدد بالمعهد

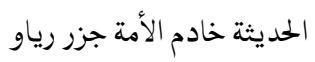

para santri. Ustadz menggunakan metode mubasyarah (langsung) dalam memberikan arti kosa kata, yaitu dengan membawakan benda/gambar yang dimaksud dalam bahasa arab sehingga para santri memahami arti kata secara langsung dengan melihat benda yang dimaksud. Setelah menyampaikan beberapa kosa kata kemudian guru membagi kelas menjadi dua orang dalam setiap kelompok saling berhadapan. Selanjutnya guru membagikan gambar pada tiap-tiap kelompok untuk bertanya satu sama lainnya secara bergantian.

Tahap selanjutnya setelah memberikan kosakata dan para santri memahaminya dan mampu mengucapkannya secara benar, ustadz memberikan contoh bagaimana diterapkan dikeseharian dalam bentuk kalimat. Kemudian guru meminta beberapa santri untuk memberikan contoh kalimat sebagaimana yang dicontohkan.

Kegiatan ini diulang oleh ustadz selama kurang lebih 1 minggu dengan penambahan materi dan kosakata setiap harinya. Setiap pertemuan dilakukan latihan percakapan dengan materimateri yang telah diberikan berguna untuk mengasah pendengaran santri dengan apa yang didengar dan memberikan motivasi agar berani berbicara dengan bahasa arab sesuai dengan kaidahnya.

Tes maharah kalam menggunakan tes lisan seputar adawatul yaumiyah (الأدوات اليومية) satu persatu di tes oleh ustadz. Berdasarkan data hasil tes yang diadakan pada santri baru kelas 1 MTs pondok pesantren Khadimul Ummah, diketahui 52 santri yang ada 
Ramandhan Rudwi Hantoro : فعالية برنامج تشجيع اللغة في ترقية مهارة الكلام لطلاب الجدد بالمعهد الحديثة خادم الأمة جزر رياو

seluruhnya mengikuti tes baik preetest maupun posttest. Dari 52 santri hanya sebanyak 7 santri yang dinyatakan lulus preetest, sedangkan lainnya sebanyak 45 santri dinyatakan tidak lulus. Hasil posttest menunjukkan sebanyak 3 santri dinyatakan tidak lulus, sedangkan 49 santri lainnya dinyatakan lulus. Dapat disimpulkan terkait dengan efektivitas pelaksanaan program tasyji'ul lughoh untuk meningkatkan maharah kalam dengan katergori sangat baik. Adapun perhitungan persetasenya sebagai berikut:

$$
P=\frac{49}{52} \times 100 \%=94 \%
$$

Berdasarkan hasil penelitian, diketahui bahwa program tasyji'ul lughoh yang diselenggarakan pondok pesantren Khadimul Ummah untuk santri-santri baru sangat efektif. Program tasyji'ul lughoh menekankan penguasaan kosakata bahasa Arab, dan penerapannya dalam kehidupan sehari-hari bertujuan untuk mengembangkan kemahiran maharah kalam pada santri. Materimateri pada program ini dirancang mengambil tema-tema yang sangat dekat dengan kehidupan sehari-hari santri agar lebih mudah diterapkan dan dipraktekan dalam percakapan bahasa arab. Materi yang diberikan dalam Tasyji'ul Lughoh disajikan dalam bentuk kosakata, cerita, dan juga percakapan.

Pelaksanaan program ini bagi santri baru berdasarkan uji pretest dan posttest serta melihat hasil perhitungan efektivitasnya maka dapat disimpulkan bahwa program tasyji'ul lighoh untuk 
Ramandhan Rudwi Hantoro : فعالية برنامج تشجيع اللغة في ترقية مهارة الكلام لطلاب الجدد بالمعهد الحديثة خادم الأمة جزر رياو

meningkatkan maharah kalam santri baru di pondok pesantren Khadimul Ummah sangat efektif dengan presentase sebesar 94\% (persen) atau sebanyak 49 santri dinyatakan lulus atau berhasil dari total santri 52 orang santri.

Keberhasilan program Tasyji'ul lughoh dalam meningkatkan maharah kalam santri baru memperkuat pendapat yang mengatakan bahwa dalam mempelajari bahasa asing perlu mempraktekkan bahasa itu sendiri sehingga bisa mengintegrasikan antar Maharat. Hasil ini juga menunjukkan bahwa pembentukan lingkungan yang mendukung untuk berbahasa sangatlah penting. Meskipun begitu keberhasilan ini juga bisa diartikan bahwa membiasakan berbicara bahasa Arab merupakan cara yang efektif dan efisien apalagi jika didukung dengan lingkungan pondok pesantren.

\section{Kesimpulan}

Hasil penelitian tentang keefektifan program Tasyji'ul Lughoh dalam meningkatkan maharah kalam santri baru di pesantren Khadimul Ummah menunjukkan sangat efektif dengan persentase nilai keefektivan sebesar 94\% (persen) yaitu masuk dalam kategori sangat baik. Dari hasil penelitian ini maka dapat disarankan kepada pondok pesantren Khadimul Ummah agar membuat rancangan program tasyji'ul lughoh yang diterapkan kepada seluruh santri disetiap jenjang dengan level yang lebih tinggi menyesuaikan kebutuhan tiap jenjang. 
Ramandhan Rudwi Hantoro : فعالية برنامج تشجيع اللغة في ترقية مهارة الكلام لطلاب الجدد بالمعهد الحديثة خادم الأمة جزر رياو

\section{DAFTAR PUSTAKA}

al-Khalifah, Hasan Ja'far, Fushul fi Tadris al-Lughoh al-'Arabiyah, Riyadh: Maktabah al-Rusyd, 2002

Al-Naqah, Mahmud Kamil, Ta'limul Lughah 'Arabiyah Linnathiqina bilughati ukhra, Makkah: Ummul Qura University, 1985

Hermawan, Acep, Metodologi Pembelajaran Bahasa Arab, Bandung: PT Remaja Rosdakarya, 2011

Habibah, Nur, Lingkungan Artifisial dalam Pembelajaran Bahasa Arab dalam dalam Arabiyat: Jurnal Pendidikan Bahasa Arab dan kebahasa araban, UIN Syarif Hidayatullah, 2016

'Ilyan, Ahmad Fuad Mahmud, al-Maharat al-Lughawiyah wa Tharaiqa Tadrisiha. Riyadh: Darul Muslim Lin Nasyr wat Tauzi', 1431 H

Munawwir, Ahmad Warson, Kamus Bahasa Arab, Surabaya: Pustaka Progresif, 2001

Sokah, Umar Assasudin, Problematika Pengajaran Bahasa Arab dan Bahasa Inggris, Yogyakarta: Nur Cahaya, 1982

Siti Jaroyatun Ni'mah dan Muhammad Nasirudin, efektifitas Kitab 'Arabiyah linnasyiin untuk meningkatkan Maharah Qiraah dan Kalam di Kelas 1 Marhalah 2 Madrasah Diniyah Nurul Ummah Putri Kota Gede, dalam Maharaat: Jurnal Pendidikan Bahasa Arab, UIN Sunan Kali Jaga, 2002

Tim Penyusun Pusat Bahasa, Kamus Bahasa Indonesia, Jakarta: Pusat Bahasa, 2008

Widoyoko, Eko Putro, Evaluasi Program Pembelajaran, Jogjakarta: Pustaka Pelajar, 2009

Zaenudin,Radliyah, Strategi Alternatif Pembelajaran Bahasa Arab, Yogyakarta: Pustaka Rihlah Grup, 2005. 